\title{
A ECONOMIA E A RELEVÂNCIA DA JURISPRUDÊNCIA DO TRIBUNAL DE JUSTIÇA DA UNIÃO EUROPEIA NO PROCESSO DE INTEGRAÇÃO: REFLEXÕES ACERCA DO ACÓRDÃO PROFERIDO NO PROCESSO C-393/16 - CASO CHAMPAGNER SORBET
}

\author{
Cristiane Rosália Maestri Böell ${ }^{1}$
}

\section{RESUMO}

O presente artigo tem por escopo examinar a tensão entre regulamentação e liberdade de mercado na União Europeia, por meio do estudo do Acórdão do TJUE no caso "Champagner Sorbet", que aborda o mercado interno europeu, sustentáculo instrumental de integração da União, com enfoque na política adotada pelos mercados agrícolas e questões relacionadas às Denominações de origem protegida. O enfoque singe-se à participação ativa no projeto de integração europeia do pensamento ordoliberal e o importante papel do TJUE na salvaguarda da independência da organização do mercado comum.

Palavras-chave: União Europeia. Economia. Mercado Comum. Denominações de origem protegida (DOP). Integração europeia.

\section{THE ECONOMY AND THE RELEVANCE OF JURISPRUDENCE OF THE EUROPEAN UNION COURT IN THE INTEGRATION PROCESS: REFLECTIONS ON THE JUDGMENT IN CASE C-393/16 - CHAMPAGNER SORBET CASE}

\begin{abstract}
The purpose of this article is to examine the tension between regulation and market freedom in the European Union, by studying the Judgment of the CJEU in the Champagner Sorbet case, which addresses the European internal market, an instrumental support of integration of the Union, focusing on the policy adopted by the agricultural markets and issues related to the Protected Designations of Origin. The focus is simply on active participation in the project for the European integration of ordoliberal thinking and the main role of the CJEU in safeguarding the independence of the organization of the common market.
\end{abstract}

Keywords: European Union. Economy. Common Market. Protected designations of origin (PDO). European integration.

\section{INTRODUÇÃO}

O presente trabalho tem por escopo investigar a integração econômica como instrumento da integração política na União Europeia, partindo-se da premissa, entretanto, de

1 Mestranda em Ciência Jurídica pela Universidade do Vale do Itajaí (SC, Brasil) e em Direito da União Europeia pela Universidade do Minho (Braga, Portugal). Especialista pela Universidade Federal de Santa Catarina em Ministério Público, Direito e Sociedade (2003). Bacharel em Direito pela Universidade Federal de Santa Catarina (1996). Membro do Ministério Público do Estado de Santa Catarina. Pesquisa sobre Democracia, Constitucionalismo e Direito da União Europeia, com ênfase para os direitos das mulheres. 
que a integração econômica, transcendendo a conveniência política, apresenta razões eminentemente econômicas no contexto da reconstrução europeia do pós-guerra, com vistas à coexistência pacífica.

Diante disso, o mercado interno e a união econômica e monetária são instrumentos da realização dos objetivos da União e responsáveis pelo aprofundamento da integração europeia, exigindo-se dos Estados-Membros o aval na institucionalização de disciplina comercial, econômica e monetária, sem prejuízo de disciplinamento financeiro, fiscal e social.

Contexto em que o trabalho do Tribunal de Justiça da União Europeia (TJUE) contribuiu largamente para a constitucionalização dos Tratados, definindo uma verdadeira Constituição Econômica Europeia e criando as condições para a União Econômica e Monetária (UEM), proposta primeiramente pelo Plano Werner, na década de 70 e posteriormente pelo Plano Delors, "que está na base de todo o desenho consagrado em Maastricht” (FERREIRA, 2012, p. 555).

Nesse cenário, a teoria ordoliberal ${ }^{2}$, que tem por objetivo uma economia liberal, de livre mercado e protegida por princípios constitucionais garantidores da não intervenção estatal e não ocorrência de distorções concorrenciais, contribuiu para o debate, a compreensão e a construção da integração europeia, viés que as disposições referentes à liberdade de circulação e à concorrência transformaram-se em fundamento da Constituição europeia e na sua fonte de legitimidade. Aliás, o art. 119. ${ }^{\circ}$ do TFUE, retrata "o triunfo da visão liberal da integração económica, balizando as políticas económicas nacionais pelos princípios de uma economia de mercado aberto e de livre concorrência [...]” (FERREIRA, 2012, p. 557).

No âmbito do mercado comum, no espaço europeu, para se garantir sua regulamentação, a União Europeia tem conduzido o processo de regulação do mercado mediante harmonização e unificação das normas comunitárias com as nacionais, por meio de substituição dessas por aquelas, favorecendo a integração de mercado, seara em que a atuação do Tribunal de Justiça da União Europeia (TJUE) tem fundamental importância. O Acórdão Cassis de Dijon é um marco em que o Tribunal de Justiça e o mercado passaram a ter maior

2 1. Originou-se, etimologicamente, na combinação do liberalismo com o conceito de ordem (a palavra latina ordo, que possui significado de ordem). 2. "Doutrina de matriz liberal que defende a necessidade de regras e instituições políticas fortes, a fim de garantir a existência de um mercado livre e concorrencial, que sirva de base estruturante a uma ordem política democrática, capaz de assegurar um mínimo de garantias sociais." (ORDOLIBERALISMO, 2021) 


\section{A ECONOMIA E A RELEVÂNCIA DA JURISPRUDÊNCIA DO TRIBUNAL DE JUSTIÇA DA UNIÃO EUROPEIA NO PROCESSO DE INTEGRAÇÃO: REFLEXÕES ACERCA DO ACÓRDÃO PROFERIDO NO \\ PROCESSO C-393/16 - CASO CHAMPAGNER SORBET}

papel como impulsionadores da integração econômica e política, promovendo equilíbrio institucional dos Tratados constitutivos. Desde então, o TJUE passou a ter participação decisiva em nível de regulação do mercado comum (MADURO, 2006, p. 106-131).

Assim, pretende-se, pelo estudo aqui proposto, compreender, a partir da regulação do mercado interno e da jurisprudência do TJUE a respeito, especificamente pela análise do acórdão proferido no caso Champagner Sorbet, processo C-393-16, como a economia tem se apresentado como o fator preponderante no processo de integração da União Europeia. $\mathrm{O}$ estudo do acórdão referido também se propôs a trazer reflexões sobre meandros do mercado agrícola, apresentando-se interpretação das normas relativas à exploração da reputação de uma denominação de origem, de utilização abusiva, de imitação ou evocação e de indicações falsas ou falaciosas e a possibilidade de induzir em erro o público relevante relativamente à origem geográfica de um produto, com vistas a proteção dos nomes de produtos específicos para promover suas características únicas, vinculadas à sua origem geográfica e ao know-how tradicional. Para os fins pretendidos, utilizou-se a técnica do referente e aplicou-se o método indutivo.

\section{O MERCADO INTERNO COMO INSTRUMENTO ESSENCIAL À INTEGRAÇÃO DA UNIÃO EUROPEIA}

A integração econômica é historicamente o principal instrumento de integração política e, por conseguinte, da construção e integração europeia. Nesse sentido, conforme dispõe o art. $3^{\circ}$, n. $^{\circ} 3$, do TUE (Tratado da União Europeia), o mercado interno e a união econômica e monetária são instrumentais para a realização dos objetivos da União de promoção da paz, dos valores aos quais se funda (art. 2. ${ }^{\circ}$ do TUE) e bem-estar dos povos europeus. Assim, para Froufe e Gomes (2016, p. 450):

\footnotetext{
A promoção da paz, dos seus valores e o bem-estar dos povos europeus são, assim, assumidos pela União como objetivos mediatos, referências, do desenvolvimento de sua ação e, simultaneamente, justificativos da sua existência. Para tal, para alcançar os objetivos enunciados (ou nortear permanentemente a sua própria ação e o seu desenvolvimento), a União tem como instrumentos (objetivos instrumentais, mais imediatos) quer o estabelecimento de um mercado interno, quer de uma união económica e monetária.
}

Nesse viés, o processo de integração europeia apresenta caráter intervencionista, na medida em que as políticas supranacionais guardam concomitância entre o universo da 
integração e o âmbito da soberania dos Estados-membros, o que pressupõe a existência de um disciplinamento supranacional, para que tais políticas, em matéria de regulação dos mercados, sejam coordenadas, garantindo a convergência dos seus resultados no plano nacional. Impõese, então, que, em uma economia de grupo, haja certa ordem disciplinadora, comercial, econômica e monetária, ou seja,

a necessária institucionalização de uma forma de governo auto imposta para os
Estados que se integram, especialmente atenta ao rigor (sensível aos conceitos de
"boa governança" e de uma permanente adountability), portadora de precauções
acrescidas de transparência e de responsabilidade em matéria de gestão e de
definição de políticas públicas. (FROUFE; GOMES, 2016, p. 454-455)

O mercado interno da UE (União Europeia), pelo alcance que lhe é conferido pelo art. 26, n. 2 do TFUE, traduz-se como espaço livre de barreiras estatais, físicas, aduaneiras, comerciais, técnicas, dentre outras, ou seja, o "mercado interno compreende um espaço sem fronteiras internas no qual a livre circulação das mercadorias, das pessoas, dos serviços e dos capitais é assegurada de acordo com as disposições dos tratados."

O dispositivo supramencionado tem sua redação originária dada pelo Ato Único Europeu $(\mathrm{AUE})^{3}$ e veio cumprir o propósito de criação em 1993 de um mercado "único"4 no espaço da Comunidade Europeia, reconhecida como imprescindível por Jacques Delors, então Presidente da União Europeia. Tendo em vista que o processo de construção europeia não avançava no ritmo pretendido, pois ainda persistiam muitos entraves à livre circulação e à livre concorrência, conforme relata Porto (2012, p. 270):

o Comissário Cockfiel foi encarregado de presidir a uma comissão mandatada para elaborar um Livro Branco do Mercado Único (conhecido por Relatório Cockfiel) que veio fazer uma listagem dos regulamentos e directivas que afastariam os obstáculos físicos, técnicos e fiscais que impediam a existência de um mercado comum: um conjunto inicialmente previsto de 286 e que veio a ser de 267 diplomas. Assim se chegaria ao "mercado interno", ou "único".

Entendeu-se também que para o avanço do mercado único havia necessidade de mudar o processo legislativo que foi previso no início das Comunidades, passando a não mais se exigir unanimidade na aprovação dos diplomas do Conselho neste domínio. Já em 1997,

3 O Acto Único Europeu, que entrou em vigor em 1 de julho de 1987, introduziu alterações nos Tratados que instituem as Comunidades Europeias e consagrou a cooperação política.

4 Na designação do texto do Tratado, "interno," "mas na tradução à letra de "single" market - dando a ideia correta e desejável, de que não se trata de um mercado "fechado', protegido, em relação ao exterior, bem como de que não se trata de um mercado nacional, mas sim de um mercado comum a vários países". (PORTO, 2012, p. 270). 


\section{A ECONOMIA E A RELEVÂNCIA DA JURISPRUDÊNCIA DO TRIBUNAL DE JUSTIÇA DA UNIÃO EUROPEIA NO PROCESSO DE INTEGRAÇÃO: REFLEXÕES ACERCA DO ACÓRDÃO PROFERIDO NO \\ PROCESSO C-393/16 - CASO CHAMPAGNER SORBET}

com escopo de aprofundar o mercado único, por iniciativa da Comissão, instituiu-se o "Plano de Açção para o Mercado Único”, que nas palavras do então Presidente Barroso, "o mercado único foi, e continua a ser, a pedra angular da integração da Europa e do crescimento sustentável," vindo recentemente agregar-se outras importantes inciativas da Comissão, dentre elas a Estratégia Europa 2020. (PORTO, 2012, p. 270-271).

Nessa esteira, também compondo o ordenamento jurídico que disciplina o mercado interno europeu, perfilham-se regras específicas às políticas adotadas pela UE, dentre elas a política agrícola comum, e que, para se atingir seus objetivos, estabeleceu uma organização comum dos mercados agrícolas (art. 38 e seguintes do TFUE).

A política Agrícola Comum (PAC) nasceu em 1962, com o objetivo de fornecer alimentos a preços acessíveis à comunidade europeia e um padrão de vida digno aos agricultores. Hoje, estabelecendo-se a base jurídica da PAC pelo TFUE e pelo Regulamento (UE) $1307 / 2013^{5}$, Regulamento (UE) $1308 / 2013^{6}$, Regulamento (UE) $1305 / 2013^{7}$ e Regulamento (UE) 1306/2013 ${ }^{8}$, gerida e financiada a partir dos recursos do orçamento da UE, tem-se por objetivo, dentre outros, o apoio aos agricultores e melhora da produtividade agrícola, inclusive com promoção de empregos nas indústrias agropecuárias, garantindo um fornecimento estável de alimentos a preços acessíveis, com uma prática agrícola sustentável (THE COMMON..., 2019).

Assim, as indicações geográficas protegem os produtos agrícolas e alimentos, além de bebidas (espirituosas e vinhos), de sofrerem uma utilização abusiva ou contrafacções ou imitações, garantindo a origem do produto. Os regimes de qualidade instituídos pela UE asseguram a proteção dos nomes dos produtos no caso de existir uma relação intrínseca entre as qualidades ou características dos produtos e a respectiva origem geográfica, interessando ao nosso estudo as denominações de origem protegidas (DOP) ${ }^{9}$, para produtos agrícolas, alimentos e vinhos. Conforme a Comissão Europeia:

A política de qualidade da UE visa proteger os nomes de produtos específicos para promover suas características únicas, vinculadas à sua origem geográfica e ao know-

\footnotetext{
Estabelece regras para pagamentos diretos aos agricultores.

Trata da organização comum dos mercados de produtos agrícolas.

Estabelece apoio ao desenvolvimento rural.

Dispõe sobre financiamento, gestão e acompanhamento da política agrícola comum.

9 Existem mais dois tipos de regimes de qualidade na UE, as indicações geográficas protegidas (IGP) e as indicações geográficas (IG).
} 
how tradicional. Os nomes de produtos podem ser concedidos com uma 'indicação geográfica' (IG) se eles tiverem um link específico para o local onde são feitos. O reconhecimento GI permite que os consumidores confiem e distingam produtos de qualidade, além de ajudar os produtores a comercializar melhor seus produtos. Reconhecidas como propriedade intelectual, as indicações geográficas desempenham um papel cada vez mais importante nas negociações comerciais entre a UE e outros países. (QUALITY..., 2019)

No contexto do mercado interno e especificamente da organização comum dos mercados agrícolas, segue a análise do julgado do Tribunal de Justiça, o qual proclama o direito, por meio de reenvio prejudicial, apresentando interpretação de normas de direito da União, tocante a interpretação das normas concernentes à exploração da reputação de uma denominação de origem, de utilização abusiva, de imitação ou evocação e de indicações falsas ou falaciosas e a possibilidade de induzir em erro o público relevante em relação à origem geográfica de um produto.

\section{A JURISPRUDÊNCIA DO TRIBUNAL DE JUSTIÇA DO UNIÃO EUROPEIA NO CASO CAMPAGNER SORBET}

\subsection{QUADRO FÁTICO E JURÍDICO DO PEDIDO DE DECISÃO PREJUDICIAL}

O processo C-393-16 traz à baila a questão da comercialização, por uma cadeia de supermercados alemã, a partir do final do ano de 2012, de uma sobremesa gelada (sorvete) que continha $12 \%$ de champagne, denominado "Champagner Sorbet". O Bundesgerichtshof (Tribunal Federal, Alemanha) suscitou o reenvio prejudicial, pois teria, em seguida, que decidir se procedia o pedido de cessação da venda do produto, formulado pelo Comité Interprofessionnel $d u$ Vin de Champagne (CIVC), que defendia os interesses dessa denominação de origem protegida (DOP) em face de Aldi Süd Dienstleistungs-GmbH \& Co. $O H G^{10}$.

De acordo com os autos do reenvio prejudicial, fez-se necessária a interpretação do Regulamento (CE) n. ${ }^{\circ}$ 1234/2007 do Conselho, de 22 de outubro de 2007, que estabelece uma organização comum dos mercados agrícolas e disposições específicas para certos produtos agrícolas, e suas alterações, e do Regulamento (UE) n. ${ }^{\circ}$ 1308/2013 do Parlamento Europeu e

${ }^{10}$ Representada por Aldi Süd Dienstleistungs-GmbH, anteriormente Aldi Einkauf GmbH \& Co.OHG Süd sendo interveniente Galana NV. 


\section{A ECONOMIA E A RELEVÂNCIA DA JURISPRUDÊNCIA DO TRIBUNAL DE JUSTIÇA DA UNIÃO EUROPEIA NO PROCESSO DE INTEGRAÇÃO: REFLEXÕES ACERCA DO ACÓRDÃO PROFERIDO NO \\ PROCESSO C-393/16 - CASO CHAMPAGNER SORBET}

do Conselho, de 17 de dezembro de 2013, que prevê uma organização comum dos mercados dos produtos agrícolas. Registre-se que a referência constante do reevio diz respeito tanto ao Regulamento n. ${ }^{\circ}$ 1234/2007, em vigor à época dos fatos no litígio principal e o Regulamento n. ${ }^{\circ} 1308 / 2013$, que o substituiu a partir de $1^{\circ}$ de janeiro de 2014 , posto que a interpretação deste último é também necessária, já que o requerimento de cessação da utilização da DOP "Champagne" avança para o futuro, fazendo-se mister que o Tribunal de Justiça pronuncie-se, assim, inclusive sob a égide das disposições aplicáveis ao tempo em que a decisão for proferida.

E, assim, o órgão jurisdicional de reenvio questionou, à luz das disposições supracitadas, se a atuação do responsável pela distribuição do sorvete em questão é legítima ao explorar a reputação do vinho espumante francês que beneficia de uma DOP, e se, nesse âmbito, "só cobre as indicações falaciosas que são suscetíveis de criar no espírito do público relevante uma impressão errada sobre a origem geográfica do produto ou se cobre também as indicações falaciosas quanto às qualidades essenciais desse produto" (UNIÃO EUROPEIA, 2017a, considerando 28).

Diante disso, o processo seguiu seu trâmite no Tribunal de Justiça, com apresentação de observações escritas pelo CIVC, pela Galana NV, e pelos Governos francês e português, bem como pela Comissão Europeia, com posterior realização de audiência e apresentação de Conclusões pelo Advogado-Geral.

Segundo o Advogado-Geral, em suas Conclusões, embora o Tribunal detenha vasta jurisprudência relativa às denominações de origem protegida (DOP) e às indicações geográficas protegidas (IGP), o presente processo oportunizará “[...] alargar às situações em que um vinho espumante (champagne) abrangido por uma DOP é incorporado - e se inclui na apresentação - como ingrediente de um gênero alimentício" (UNIÃO EUROPEIA, 2017b, considerando 3).

Veja-se a imagem do produto em discussão apresentada nas Conclusões pelo Advogado-Geral Manuel Campos Sánchez-Bordona: 
Figura 1 - Imagem do produto apresentada nas Conclusões do

Advogado-Geral Manuel Campos Sánchez-Bordona

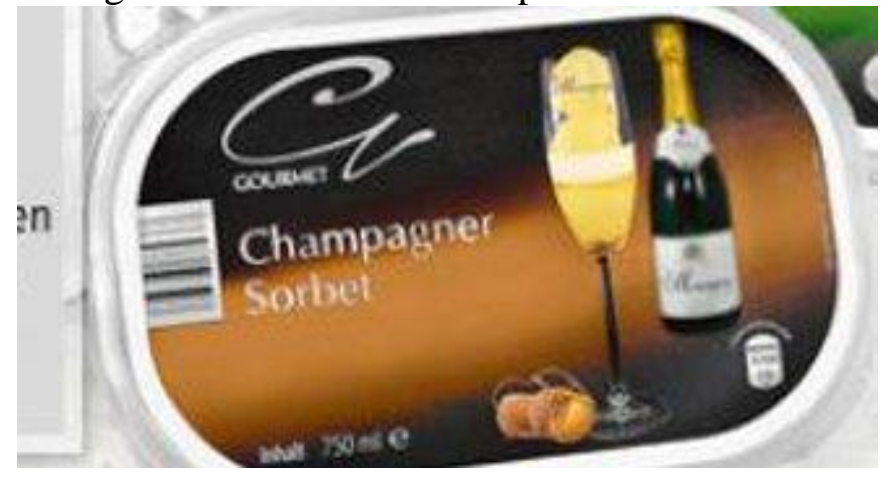

Fonte: UNIÃO EUROPEIA, 2017b, considerando 14

\subsection{QUESTÕES PREJUDICIAIS NO ÂMBITO DO PROCESSO C-393-16}

Nessa perspectiva, o Supremo Tribunal Federal da Alemanha (Bundesgerichtshof), pelos fatos e fundamentos apresentados acima, não sem antes ter suspendido a instância, submeteu ao Tribunal de Justiça as seguintes questões prejudiciais, as quais ora se analisa, de conformidade com o Acórdão prolatado no processo:

1. O pedido do tribunal de reenvio é no sentido de que se clarifique, em sede preliminar, o âmbito de aplicação do artigo $118 .^{\circ}-\mathrm{M}, \mathrm{n}^{\mathrm{o}}{ }^{2}$, alínea a, ii, do Regulamento n. ${ }^{\circ} 1234 / 2007$, ou seja, pretende "que se esclareça se abrange situações como a dos autos, em que a DOP «Champagne» é parte do nome de um sorvete que contém uma determinada quantidade desse vinho espumante" (UNIÃO EUROPEIA, 2017a, considerando 23).

Assim, para melhor compreender a tarefa de interpretação, mostra-se necessária a leitura do inteiro teor do artigo $118 .{ }^{\circ}-\mathrm{M}$, n. $^{\circ} 2$, do Regulamento n. ${ }^{\circ}$ 1234/2007, do Conselho, de 22 de outubro de 2007, que estabelece uma organização comum dos mercados agrícolas e disposições específicas para certos produtos agrícolas (Regulamento «OCM única»), incluindo uma graduação de condutas desleais nesse âmbito das denominações de origem, indicações geográficas e menções tradicionais no setor vitivinícola:

Artigo $118^{\circ} .-\mathrm{M}-$ Protecção

$[\ldots]$

2. As denominações de origem protegidas e as indicações geográficas protegidas e os vinhos que utilizam esses nomes protegidos em conformidade com o caderno de especificações são protegidos contra:

a) Qualquer utilização comercial directa ou indirecta de um nome protegido: 


\section{A ECONOMIA E A RELEVÂNCIA DA JURISPRUDÊNCIA DO TRIBUNAL DE JUSTIÇA DA UNIÃO EUROPEIA NO PROCESSO DE INTEGRAÇÃO: REFLEXÕES ACERCA DO ACÓRDÃO PROFERIDO NO \\ PROCESSO C-393/16 - CASO CHAMPAGNER SORBET}

i) por produtos comparáveis não conformes com o caderno de especificações do nome protegido; ou

ii) na medida em que tal utilização explore a reputação de uma denominação de origem ou de uma indicação geográfica;

b) Qualquer usurpação, imitação ou evocação, ainda que a verdadeira origem do produto ou serviço seja indicada ou que o nome protegido seja traduzido ou acompanhado por termos como «género», «tipo», «método», «estilo», «imitação», «sabor», «como» ou similares;

c) Qualquer outra indicação falsa ou falaciosa quanto às proveniência, origem, natureza ou qualidades essenciais do produto, que conste do acondicionamento ou da embalagem, da publicidade ou dos documentos relativos ao produto vitivinícola em causa, bem como o acondicionamento em recipientes susceptíveis de criar uma opinião errada sobre a origem do produto;

d) Qualquer outra prática susceptível de induzir o consumidor em erro quanto à verdadeira origem do produto.

Diante disso, inquestionável é que a interpretação dada ao Direito da União no Acórdão Bureau National Interprofessionnel du Cognac (UNIÃO EUROPEIA, 2011, considerando 55), marca que incorpora uma indicação geográfica de bebida espirituosa originária de França, aplica-se ao presente caso, não obstante a apreciação tenha recaído sobre o Regulamento n. ${ }^{\circ} 110 / 2008$, pois o seu art. $16^{\circ}$, como bem concluiu o Advogado-Geral (UNIÃO EUROPEIA, 2017b, considerando 45), guarda semelhança, tanto literal como teleológica, com o artigo $118 .{ }^{\circ}-\mathrm{M}$ do Regulamento n. ${ }^{\circ}$ 1234/2007. Do teor do acordão ora citado, extrai-se que, independentemente da proteção que a legislação francesa dispense, o termo "Cognac" é protegido como indicação geográfica no direito da União, desde 15 de junho de $1989^{11}$, sendo que:

O artigo $16^{\circ}$., alíneas a) a d), do Regulamento n. ${ }^{\circ}$ 110/2008 prevê diversos casos em que a comercialização de um produto é acompanhada de uma referência expressa ou implícita a uma indicação geográfica, em condições susceptíveis quer de induzir o público em erro ou, pelo menos, de criar no seu espírito uma associação de ideias quanto à origem do produto, quer de permitir ao operador aproveitar-se indevidamente da reputação da indicação geográfica em questão. (UNIÃO EUROPEIA, 2011, considerando 46)

E, no caso do Acórdão Comité Interprofessionnel du Vin de Champagne (CIVC), de 20 de dezembro de 2017, objeto da análise, o Tribunal procedeu cotejo com a situação jurídica apreciada no Acórdão Bureau National Interprofessionnel du Cognac, reconhecendo ser entendimento jurisprudencial aplicável ao caso "Champagner Sorbet”:

[...] o uso, numa marca, de uma indicação geográfica ou de um termo correspondente a essa indicação ou à sua tradução, para identificar produtos (à

${ }^{11}$ Data em que entrou em vigor o Regulamento n. ${ }^{\circ} 1576 / 89$. 
época, bebidas espirituosas) que não cumpriam as especificações correspondentes, constitui uma utilização comercial direta dessa indicação geográfica, na acepção do artigo 16. ${ }^{\circ}$, alínea a), do Regulamento n. ${ }^{\circ}$ 110/2008. (UNIÃO EUROPEIA, 2017a, considerando 34)

Por conseguinte, o Tribunal de Justiça respondeu positivamente a primeira questão prejudicial, ou seja, que no âmbito de aplicação o caso em que uma DOP - "Champagne" - é usada como parte da designação de um gênero alimentício, não cumpre o caderno de especificações relativo a essa DOP (mas que tem ingrediente constante do referido caderno).

2. Diante da resposta afirmativa no item acima, o reenvio é no sentido de questionar se os regulamentos em voga devem ser interpretados no sentido de que produtos alimentícios, nas condições jurídicas imediatamente aludidas, constituem:

exploração da reputação de uma denominação de origem, quando a designação do gênero alimentício corresponde à denominação habitual de venda do público relevante e o ingrediente foi acrescentado em quantidade suficiente para conferir ao produto uma propriedade essencial? (UNIÃO EUROPEIA, 2017b, considerando 21.2)

Ao se denominar um gênero alimentício, como no caso do processo principal, que contenha ingrediente que beneficia de uma DOP, pois supostamente o sabor gerado por esse ingrediente constitui característica essencial, cabe ao órgão jurisdicional nacional apreciar, com base na prova apresentada, se esse produto tem um gosto produzido, essencialmente, pela presença do champanhe na sua composição.

Decidiu-se, então, que devem ser interpretados os artigos $118 .^{\circ}-\mathrm{M}, \mathrm{n}^{\circ}{ }^{\mathrm{o}} 2$, alínea a, ii, do Regulamento n. ${ }^{\circ} 1234 / 2007$ e $103 .^{\circ}$, n. $^{\circ} 2$, alínea a, ii, do Regulamento n. ${ }^{\circ}$ 1308/2013, no sentido de que a utilização de uma DOP (quando parte da designação sob a qual é vendido um gênero alimentício que não cumpre o caderno de especificações relativo a referida DOP), mas que contém um ingrediente que o cumpre, como é o caso do "Champagner Sorbet", constitui uma exploração da reputação de uma DOP, na acepção das disposições legais referidas, se esse gênero alimentício não tiver, como caráter essencial um sabor gerado, principalmente, pela existência desse ingrediente na sua composição (UNIÃO EUROPEIA, 2017a, considerando 53).

3. Devem o artigo $118 .^{\circ}-\mathrm{M}, \mathrm{n}^{\circ}{ }^{2}$, alínea b, do Regulamento . $^{\circ} 1234 / 2007$ e o art. 103. ${ }^{\circ}$, n. ${ }^{\circ}$ 2, alínea b), do Regulamento n. ${ }^{\circ} 1308 / 2013$ ser interpretados no sentido de que a utilização de uma DOP nas circunstâncias descritas na segunda questão constitui utilização abusiva, imitação ou evocação? 


\section{A ECONOMIA E A RELEVÂNCIA DA JURISPRUDÊNCIA DO TRIBUNAL DE JUSTIÇA DA UNIÃO EUROPEIA NO PROCESSO DE INTEGRAÇÃO: REFLEXÕES ACERCA DO ACÓRDÃO PROFERIDO NO \\ PROCESSO C-393/16 - CASO CHAMPAGNER SORBET}

Pelo teor da legislação imediatamente citada, ao se incorporar, na denominação do produto alimentício, um ingrediente que se beneficia da DOP, há uma utilização direta dessa DOP para estabelecer claramente uma "qualidade gustativa" a ela ligada, o que, portanto, não constitui nem uma usurpação, nem uma imitação, nem uma evocação.

Nos fundamentos da decisão, o TJUE, considerando o já analisado, entendeu que as disposições legais em questão devem ser interpretadas no sentido de que a utilização de uma DOP como parte da denominação sob a qual é vendido um gênero alimentício que não cumpre o caderno de especificações a ela relativo, contudo, contém um ingrediente que o cumpre, não constitui uma usurpação, imitação ou evocação, na acepção dessas disposições.

4. Devem o artigo $118 .^{\circ}-\mathrm{M}, \mathrm{n} .{ }^{\circ}$ 2, alínea c, do Regulamento ${ }^{\circ}{ }^{\circ}$ 1234/2007 e o artigo $103 .^{\circ}$, n. $^{\circ} 2$, alínea c, do Regulamento . $^{\circ} 1308 / 2013$ ser interpretados no sentido de que apenas são aplicáveis a indicações falsas ou falaciosas que possam inculcar no público relevante uma impressão errada quanto à origem geográfica de um produto? (UNIÃO EUROPEIA, 2017b, considerando 21, n. 4)

Em resumo, o Tribunal de reenvio pretende saber se o artigo $118 .{ }^{\circ}-\mathrm{M}, \mathrm{n} .{ }^{\circ}$ 2, alínea c, do Regulamento n. ${ }^{\circ}$ 1234/2007 é apenas aplicável às indicações falsas ou falaciosas que possam inculcar no público relevante uma impressão errada quanto à origem geográfica de um produto.

Pelo despacho de reenvio, de acordo com as conclusões do Advogado-Geral, extraise que a dúvida surge porque, para o CIVC, a proibição das referidas indicações seria geral e não abrangeria apenas as que instilem no público uma impressão errada quanto à origem geográfica do produto.

Não é caso de interpretação restritiva, posto que "a proteção que o legislador comunitário pretendeu conferir às DOP é ampla e, além da confusão relativa à origem dos produtos, procura também evitar o risco de generalização, pela diluição das DOP mediante a sua utilização indiscriminada" (UNIÃO EUROPEIA, 2017b, considerando 103).

Da interpretação dos artigos 118-M, c, do Regulamento n. ${ }^{\circ} 1234 / 2007$ e $103 .{ }^{\circ}$, n. $^{\circ} 2$, alínea c, do Regulamento n. ${ }^{\circ} 1308 / 2013$, a indicação falsa ou falaciosa pode ocorrer não somente no que se refere à origem do produto, mas, também, no tocante às suas características. Assim, se o gênero alimentício possui informação comercial (como embalagem, por exemplo) que alude a presença de "Champagne" na sua composição, levando o consumidor a pensar que dito produto beneficia de mesma proteção e qualidade que a DOP, 
sem, porém, deter as características essenciais, como o sabor, ocorrerá indicação falsa ou falaciosa.

Destarte, em resposta à quarta questão o Tribunal de Justiça decidiu que:

o artigo $118 .^{\circ}-\mathrm{M}$, n. $^{\circ} 2$, alínea c, do Regulamento devem ser interpretados no sentido de que são aplicáveis quer às indicações falsas ou falaciosas suscetíveis de criar uma impressão errada sobre a origem geográfica do produto em causa, quer às indicações falsas e falaciosas relativas à natureza ou às qualidades substanciais desse produto. (UNIÃO EUROPEIA, 2017a, considerando 64).

Pelos fundamentos jurídicos do Acórdão no caso "Champagner Sorbet", emerge a fundamental importância que o reenvio prejudical apresenta no processo de integração da União, na medida em que possibilita acessso (mesmo que indireto) do cidadão ao TJUE, estabelecendo-se como "mecanismo tendente a apreciar a compatibilidade do direito nacional com o Direito da União”, garantidor "das igualdades de posições jurídicas dos cidadões europeus" (SILVEIRA, 2011, p. 13 e 68) independente do Estado-Membro em que residam, como explica Alessandra Silveira (2011, p. 234-235), quando diz que:

a ordem jurídica europeia está ao serviço de um processo integrador e a especificidade deste ordenamento radica precisamente nos instrumentos jurídicos que se articulam com o fim de promover o objectivo da integração - de entre os quais, o reenvio prejudicial.

Nessa toada, o Direito da União submetido à apreciação, por meio do pedido de decisão prejudicial, perante o TJUE, no Acórdão analisado, respeita ao mercado interno, uma das fases preconizadas pela teoria da integração econômica e estabelecida como ferramenta para realização do objetivo da União de promoção da paz, dos seus valores e do bem-estar dos seus povos (art. 3. ${ }^{\circ}$, n. ${ }^{\circ}$ s 1 e 3, do TUE) (FROUFE; GOMES, 2016, p. 450-451). Como enfatiza Froufe e Gomes (2016), a integração econômica foi por décadas o objetivo que norteou as Instituições, podendo-se afirmar que é o principal mecanismo de integração europeia. Contudo, atualmente, as integrações política, cutural e jurídica, aliadas à integração ecconômica, têm sido o mote para a densificação da cidadania europeia, que, fiel ao valor de igualdade e não discriminação entre os nacionais da União, constitui verdadeira identidade supranacional:

As liberdades económicas definidoras, conjuntamente com a política e o direito da concorrência, da estrutura nuclear do mercado interno foram (e, em grande medida, ainda vão sendo) o trampolim que o TJUE utilizou para avançar na construção desse estatuto de "cidadão europeu". A cidadania europeia emergiu, na realidade e por via jurisprudencial, a partir (ou a pretexto) da liberdade de circulação de pessoas, nomeadamente da livre circulação de trabalhadores. O TJUE foi empreendendo a construção da cidadania europeia, a partir daquilo que o processo de construção 


\section{A ECONOMIA E A RELEVÂNCIA DA JURISPRUDÊNCIA DO TRIBUNAL DE JUSTIÇA DA UNIÃO EUROPEIA NO PROCESSO DE INTEGRAÇÃO: REFLEXÕES ACERCA DO ACÓRDÃO PROFERIDO NO \\ PROCESSO C-393/16 - CASO CHAMPAGNER SORBET}

europeu e o denominado acquis communautaire tinham solidamente edificado: uma espécie de "cidadania de mercado". (FROUFE; GOMES, 2016, p. 4)

Como destinatário de direitos fundamentais, o cidadão europeu, enquanto um dos atores do mercado interno, se não o protagonista, vê consolidar-se sua proteção enquanto consumidor, o que evidencia a relevância da sedimentação da jurisprudência do TJUE nesse domínio, já que contribui para a promoção do crescimento econômico equilibrado e da estabilidade dos preços, "numa economia social de mercado altamente competitiva que tenha como meta o pleno emprego e o progresso social, e num elevado nível de proteção e de melhoramento da qualidade do ambiente", consoante as disposições do art. $3 .^{\circ}$, n. $^{\circ} 3$ do TUE.

Na ótica de Froufe e Gomes (2016), ao abordar o direito europeu da concorrência, que ao lado do mercado interno compõe o eixo da integração econômica, enfatiza-se que talvez seja tempo de redirecionar o propósito primeiro do direito europeu da concorrência, como aponta a $\mathrm{OCDE}^{12}$, excetuando-se as hipóteses dos mercados dos novos Estados-Membros, pois "o objetivo da integração de mercados encontra-se basicamente realizado. As preocupações podem, e devem no nosso entender, focar-se, a partir de agora, na promoção da eficácia num mercado integrado". E segue o nobre Professor lusitano no sentido de que, com vistas ao enfretamento de novos desafios nesse domínio, há "necessidade de uma abordagem mais economicista", não só externado certa influência de Escola de Chicago, conforme Manuel Porto, mas indo um pouco mais além, "na esteira de Niels e Kate" (FROUFE; GOMES, 2016, p. 500-504), pela Escola de Harvard. Assim, "entre a regra da ilegalidade per se da fixação de preços mínimos nas relações verticais, defendida por Harvard, [...] ou da legalidade per se de Chicago, [...] o Supremo Tribunal escolheu seguir pelo caminho (conciliador) da rule of reason"13.

E na abordagem relativa à eficácia do mercado, importa refletir, sob o enfoque metodológico, o necessário redirecionamento de exame da questão, pois a União Europeia tem se utilizado de uma forma mais intensa de conceitos jurídicos em detrimento dos conceitos econômicos, sob influxo da teoria econômica alemã ordoliberal, o que tem apresentado soluções não justificáveis sob o aspecto da eficiência da econômica; "a desejada,

12 Organização para a Cooperação e Desenvolvimento Econômico, que tem objetivo discutir políticas públicas e econômicas no contexto democrático e atenção às regras de mercado.

${ }^{13}$ Froufe e Gomes referem-se às decisões da Suprema Corte dos Estados Unidos, Leegin Creative Leather Products, Inc. v. PSKS, Inc, acórdão de 28 de junho de 2007 e Weyerhaeuser U.S.: 2006. 
senão mesmo inevitável alteração, passará, provavelmente, por uma aproximação, ou, pelo menos, uma consideração atenta às tendências atuais do antitrust da visão da denominada post-Chicago econimics" (FROUFE; GOMES, 2016, p. 501-502).

Nessa senda, Froufe e Gomes (2016) enfatizam que a "economia social de mercado," como "o seu protagonismo em termos de enunciação normativa, agora assinalado e adquirido com Lisboa - mais do que indicar uma mudança do sentido da Constituição económica da EU”, poderá tão somente direcionar para um retorno a algumas das origens do processo de integração/ influências ordoliberais, mas que "será especialmente interessante e relevante se o contextualizarmos, agora, em uma fase pós-Brexit e quando se avança para um debate institucional, aberto, desde logo pela Comissão, sobre o futuro da Europa" (FROUFE, 2017, p. 128-129).

\section{CONSIDERAÇÕES FINAIS}

No presente artigo, verificou-se que a interpretação do direito da União Europeia no sentido de alargar às hipóteses que um vinho espumante (champagne), abrangido por uma DOP, é incorporado como ingrediente de um gênero alimentício, além de nortear o Tribunal de Justiça Alemão, autor do reenvio prejudicial, no julgamento do caso concreto, mais uma vez abriu caminho para a compatibilização entre o direito nacional e as normas jurídicas europeias, além do que, em atenção ao princípio do precedente vinculativo, contribui, uma vez mais, para a construção do padrão de jusfundamentalidade e materialização da cidadania europeia, intensificando o processo de integração.

Além de tudo, o pedido de decisão prejudicial tem sido mecanismo destinado à realização da tutela jurisdicional e de relevância para o estabelecimento de diálogo constante entre os tribunais nacionais e TJUE, possibilitando ao juiz nacional a aplicação de um direito que se apresente uniforme a todo cidadão europeu, quando se suscita questão de Direito da União, e, portanto, contribuindo sobremaneira para o processo de integração da União.

Dessa forma, a importância do Acórdão e de tantos outros que compõe a vasta jurisprudência do TJUE, sobre a organização comum dos mercados de produtos agrícolas e especificamente sobre a proteção das denominações de origem protegida (DOP), também se dá sob a ótica da construção da cidadania europeia, pois a apreciação de temas relacionados a liberdades econômicas permite que ocorra um elevado nível de defesa dos interesses dos 


\section{A ECONOMIA E A RELEVÂNCIA DA JURISPRUDÊNCIA DO TRIBUNAL DE JUSTIÇA DA UNIÃO EUROPEIA NO PROCESSO DE INTEGRAÇÃO: REFLEXÕES ACERCA DO ACÓRDÃO PROFERIDO NO \\ PROCESSO C-393/16 - CASO CHAMPAGNER SORBET}

cidadãos enquanto consumidores, aliás, direito ancorado nas disposições do art. $169 .^{\circ}$ do TFUE e art. 38 da Carta de Direitos Fundamentais da União Europeia.

E, assim, o método de integração econômica como instrumento da integração política, apresentou-se, e ainda se apresenta, a via mais segura para se chegar a uma nova estruturação de desenvolvimento pacífico no espaço europeu do pós II Guerra Mundial, cujo processo para se atingir tal desiderato tem por objetivo criar condições de comércio livre e integrado, de unificação dos mercados e de circulação de todos os fatores de produção.

Do ponto de vista econômico, como abordado, há um caminho apontado para algumas aberturas ao acolhimento da teoria da Law and economics, de Coase (Escola de Chicago), retomando-se àquela premissa de que ora o Estado (e no caso em estudo, mutatis mutandis, a União Europeia) que funciona como uma "super-firma" e possui instrumentos de regulação direta, apresenta melhor eficiência econômica, ora o mercado ou a "firma" faria melhor. Apesar disso, encontrar a linha delimitadora ideal de regulação pelos Órgãos constituídos da União e pelo próprio mercado, tem sido uma discussão travada nas searas doutrinárias, legislativas, administrativas e jurisprudenciais, pois estabelecer um paradigma que privilegie a maximização dos lucros do mercado, sem prescindir de valores que também são caros à União Europeia, como o respeito à dignidade humana, a democracia, a igualdade, a justiça e solidariedade, é o grande desafio.

\section{REFERÊNCIAS BIBLIOGRÁFICAS}

FERREIRA. Eduardo Paz. Título VIII. A Política econômica e monetária. Artigo 119. In: PORTO, Manuel Lopes; GONÇALO, Anastácio (Coords.). Tratado de Lisboa: anotado e comentado. Coimbra: Almedina. 2012.

FROUFE, Pedro Madeira. Constituição económica da União Europeia, antes e depois de Lisboa (entre o princípio concorrencial e a "economia social de mercado"). UNIO: EU Law Journal, v. 3, n. 1, p. 114-129, jan. 2017. Disponível em: <https://revistas.uminho.pt/index.php/unio/article/download/323/333/648>. Acesso em: 29 mar. 2021.

FROUFE, Serafim Pedro Madeira; GOMES, José Carmelo. Mercado interno e concorrência. In: SILVEIRA, Alessandra; CANOTILHO, Mariana; FROUFE, Serafim Pedro Madeira (Coords.). Direito da União Europeia: elementos de direito e políticas da união. Coimbra: Almedina, 2016. 
MADURO, Miguel Poiares. A constituição plural: constitucionalismo e União Europeia. Cascais: Principia, 2006.

ORDOLIBERALISMO. In: DICIONÁRIO Infopédia da Língua Portuguesa. Porto: Porto Ed., 2021. Disponível em: <https://www.infopedia.pt/dicionarios/linguaportuguesa/ordoliberalismo>. Acesso em: 29 mar. 2021.

PORTO, Manuel Lopes. Parte III. As políticas e acções internas da União. Título I. O mercado interno. Art. 26. ${ }^{\circ}$ In: PORTO, Manuel Lopes; GONÇALO, Anastácio (Coords.). Tratado de Lisboa: anotado e comentado. Coimbra: Almedina. 2012.

QUALITY schemes explained. European Commission Website, 2019. Disponível em: $<$ https://ec.europa.eu/info/food-farming-fisheries/food-safety-andquality/certification/quality-labels/quality-schemes-explained>. Acesso em: 5 dez. 2019.

SILVEIRA, Alessandra. Princípios de direito da União Europeia: doutrina e jurisprudência. 2. ed. Lisboa: Quid Juris, 2011.

SILVEIRA, Alessandra; FROUFE, Pedro Madeira (colaboração). Tratado de Lisboa: versão consolidada. 4. ed. Lisboa: Quid Juris, 2019.

THE COMMON agricultural policy at a glance. European Commission Website, 2019. Disponível em: <https://ec.europa.eu/info/food-farming-fisheries/key-policies/commonagricultural-policy/cap-glance_en\#thecapafter2020>. Acesso em: 5 dez. 2019.

UNIÃO EUROPEIA. Regulamento (CE) n. 1234/2007 do Conselho, de 22 de outubro de 2007, que estabelece uma organização comum dos mercados agrícolas e disposições específicas para certos produtos agrícolas... EUR-Lex, 2007. Disponível em: <https://eurlex.europa.eu/legal-content/pt/TXT/?uri=CELEX:32007R1234>. Acesso em: 6 jan. 2020.

UNIÃO EUROPEIA. Regulamento (UE) n. 1305/2013 do Parlamento Europeu e do Conselho, de 17 de dezembro de 2013, relativo ao apoio ao desenvolvimento rural pelo Fundo Europeu Agrícola de Desenvolvimento Rural (FEADER)... EUR-Lex, 2013a. Disponível em: $<$ https://eur-lex.europa.eu/legalcontent/PT/TXT/?qid=1580080517585\&uri=CELEX:32013R1305>. Acesso em: 6 jan. 2020.

UNIÃO EUROPEIA. Regulamento (UE) n. 1306/2013 do Parlamento Europeu e do Conselho, de 17 de dezembro de 2013, relativo ao financiamento, à gestão e ao acompanhamento da Política Agrícola Comum... EUR-Lex, 2013b. Disponível em: $<$ https://eur-lex.europa.eu/legal-content/PT/ALL/?uri=CELEX\%3A32013R1306>. Acesso em: 6 jan. 2020.

UNIÃO EUROPEIA. Regulamento (UE) n. 1307/2013 do Parlamento Europeu e do Conselho, de 17 de dezembro de 2013, que estabelece regras para os pagamentos diretos aos agricultores ao abrigo de regimes de apoio no âmbito da política agrícola comum... EUR-Lex, 2013c. Disponível em: <https://eur-lex.europa.eu/legalcontent/PT/TXT/?qid=1580080517585\&uri=CELEX:32013R1307>. Acesso em: 6 jan. 2020. 


\section{A ECONOMIA E A RELEVÂNCIA DA JURISPRUDÊNCIA DO TRIBUNAL DE JUSTIÇA DA UNIÃO EUROPEIA NO PROCESSO DE INTEGRAÇÃO: REFLEXÕES ACERCA DO ACÓRDÃO PROFERIDO NO \\ PROCESSO C-393/16 - CASO CHAMPAGNER SORBET}

UNIÃO EUROPEIA. Regulamento (UE) n. 1308/2013 do Parlamento Europeu e do Conselho, de 17 de dezembro de 2013, que estabelece uma organização comum dos mercados dos produtos agrícolas... EUR-Lex, 2013d. Disponível em: <https://eur-lex.europa.eu/legalcontent/PT/TXT/?qid=1579723737219\&uri=CELEX:32013R1308>. Acesso em: 6 jan. 2020.

UNIÃO EUROPEIA. Tribunal de Justiça. Primeira Secção. Processos apensos C-4/10 e C27/10. Bureau national interprofessionnel du Cognac contra Gust. Ranin Oy. Acórdão de 14 de julho de 2011. EUR-Lex, 2011. Disponível em: <https://eur-lex.europa.eu/legalcontent/PT/TXT/?qid=1580079686972\&uri=CELEX:62010CJ0004>. Acesso em: 26 jan. 2020 .

UNIÃO EUROPEIA. Tribunal de Justiça. Segunda Secção. Processo C-393/16. Comité Interprofessionnel du Vin de Champagne contra Aldi Süd Dienstleistungs-GmbH \& Co.OHG. Acórdão de 20 de dezembro de 2017. EUR-Lex, 2017a. Disponível em: <https://eurlex.europa.eu/legal-content/PT/TXT/?qid=1580078091359\&uri=CELEX:62016CA0393>.

Acesso em: 26 jan. 2020.

UNIÃO EUROPEIA. Tribunal de Justiça. Segunda Secção. Processo C-393/16. Comité Interprofessionnel du Vin de Champagne contra Aldi Süd Dienstleistungs-GmbH \& Co.OHG. Conclusões do advogado-geral Manuel Campos Sánchez-Bordona, de 20 de julho de 2017. EUR-Lex, 2017b. Disponível em: <https://eur-lex.europa.eu/legalcontent/PT/TXT/?qid=1580078091359\&uri=CELEX:62016CC0393>. Acesso em: 26 jan. 2020 . 